OPEN ACCESS

Edited by:

Adam Strzelczyk, Universitätsklinikum Frankfurt,

Germany

Reviewed by:

Felix Von Podewils,

Universitätsmedizin Greifswald,

Germany

Susanne Knake,

Philipps University of Marburg,

Germany

Gabriel Möddel,

University Hospital Muenster,

Germany

${ }^{*}$ Correspondence:

Michael Hamerle

michaelhamerle@hotmail.com

Specialty section:

This article was submitted to

Epilepsy,

a section of the journal

Frontiers in Neurology

Received: 13 March 2018

Accepted: 15 May 2018

Published: 05 June 2018

Citation:

Hamerle M, Ghaeni L, Kowski A,

Weissinger $F$ and Holtkamp M (2018)

Alcohol Use and Alcohol-Related

Seizures in Patients With Epilepsy.

Front. Neurol. 9:401.

doi: 10.3389/fneur.2018.00401

\section{Alcohol Use and Alcohol-Related Seizures in Patients With Epilepsy}

\author{
Michael Hamerle ${ }^{1,2 *}$, Leyli Ghaeni ${ }^{2}$, Alexander Kowski ${ }^{2}$, Florian Weissinger ${ }^{2}$ and \\ Martin Holtkamp ${ }^{2}$
}

${ }^{1}$ Department of Cardiology, University Hospital Regensburg, Regensburg, Germany, ${ }^{2}$ Department of Neurology, Epilepsy-Center Berlin-Brandenburg, Charité-Universitätsmedizin Berlin, Berlin, Germany

Purpose: This study aimed to assess alcohol consumption and the occurrence of alcohol-related seizures in patients with epilepsy within the last 12 months.

Methods: In an epilepsy outpatient clinic, a standardized questionnaire was used to collect data retrospectively from consecutive adult epilepsy patients who had been suffering from the disease for at least 1 year. Logistic regression analyses were performed to identify independent predictors.

Results: A total of 310 patients with epilepsy were included. Of these, 204 subjects (65.8\%) consumed alcohol within the last 12 months. Independent predictors for alcohol use were antiepileptic drug monotherapy (OR 1.901) and physicians' advice that a light alcohol intake is harmless (OR 4.102). Seizure worsening related to alcohol consumption was reported by 37 of the 204 patients (18.1\%) who had used alcohol. All 37 subjects had consumed large quantities of alcohol prior to the occurrence of alcohol-related seizures regardless of their usual alcohol-drinking behavior. The amount of alcohol intake prior to alcohol-related seizures was at least 7 standard drinks, which is equivalent to $1.4 \mathrm{~L}$ of beer or $0.7 \mathrm{~L}$ of wine. In $95 \%$ of cases, alcohol-related seizures occurred within $12 \mathrm{~h}$ after cessation of alcohol intake. Independent predictors for alcohol-related seizures were generalized genetic epilepsy (OR 5.792) and chronic heavier alcohol use (OR 8.955).

Conclusions: Two-thirds of interviewed subjects had consumed alcohol within the last 12 months. This finding may be an underestimate due to patients' self-reporting and recall error. In all cases, the occurrence of alcohol related-seizures was associated with timely consumption of considerably large amounts of alcohol. Thus, a responsible alcohol intake seems to be safe for most patients with epilepsy. However, subjects with epilepsy and especially those with generalized genetic epilepsy should be made aware of an increased risk for seizures related to heavy alcohol consumption. Factors accompanying acute heavy alcohol intake such as altered sleep architecture, impaired adherence to antiepileptic medication, and metabolic disturbances may further facilitate the occurrence of seizures.

Keywords: alcohol-related seizures, alcohol-drinking behavior, epilepsy, generalized genetic epilepsy, alcohols

\section{INTRODUCTION}

Alcohol consumption may trigger seizures in patients with epilepsy. Yet, there is currently little knowledge on the alcohol-drinking behavior of epilepsy patients. In the 1940s, William G. Lennox comprehensively analyzed alcohol consumption and the occurrence of alcohol-related seizures in 1,254 subjects with epilepsy (1). However, only about $30 \%$ of patients used alcohol, thus excluding 
$70 \%$ from any analysis of potential alcohol-related effects on the disease. The occurrence of alcohol-related seizures was reported by $21.1 \%$ of subjects who had used alcohol, and was more often stated by patients with symptomatic than with idiopathic or cryptogenic epilepsy (as classified at that time). Apart from this, there is little research on the occurrence of alcohol-related seizures in patients with epilepsy. A double-blinded, randomized, interventional study on 52 subjects with epilepsy demonstrated that a social alcohol intake over a 4-month-period did not increase seizure frequencies (2). In another interventional study on 14 patients with epilepsy and 10 healthy controls, acute moderate alcohol consumption initially suppressed epileptiform EEG-activity. Later however, when alcohol blood levels had declined, epileptiform EEG-activity was increased. Seizures occurred in some of those subjects and a rebound phenomenon was discussed (3).

Human and animal data have shown that acute alcohol intake has a biphasic effect on the central nervous system (CNS). Initially, the inhibitory gamma-aminobutyric acid (GABA)-ergic effect of alcohol exerts CNS depressant and anticonvulsant properties $(4,5)$. In the post-alcohol state, however, when alcohol blood levels decline, neuronal excitability is increased which may facilitate the occurrence of seizures in patients with epilepsy $(6,7)$.

The use of alcohol is very common in western societies (8). In Germany, $89 \%$ of all adults had consumed alcohol within the last 12 months (9). This makes it necessary for neurologists and other physicians to advise patients with epilepsy adequately on how to handle alcohol consumption with their chronic disease. The relationship between alcohol and epileptic seizures is complex. Research has mainly focused on the prevalence and pathophysiology of acute symptomatic seizures in the context of the alcohol withdrawal syndrome in alcoholdependent subjects (10-12) and on the risk to develop epilepsy due to regular alcohol consumption $(13,14)$. However, there are only a few studies that have examined the patterns of alcohol drinking in subjects with a known history of epilepsy, and these are limited by outdated results or small sample sizes. In particular, data on seizure worsening associated with alcohol consumption in patients with epilepsy are very sparse. Therefore, we aimed (a) to systematically analyze the alcohol-drinking behavior of patients with epilepsy and (b) to identify independent predictors for alcohol use and the occurrence of alcohol-related seizures.

\section{MATERIALS AND METHODS}

\section{Data Collection Using a Standardized Questionnaire, Interview Situations, and Interview Techniques}

Between October 2008 and April 2010, consecutive patients treated at the Epilepsy Outpatient Clinic, Department of Neurology, Charité-Universitätsmedizin Berlin were informed about the study and invited to participate. The data collection on alcohol use was part of a research project systematically gathering information on nicotine, alcohol, and illicit drug use in epilepsy patients within the last 12 months. The data was collected by a standardized questionnaire (see Supplementary Material). We have published data on epilepsy and illicit drug use earlier (15). Only subjects $\geq 18$ years who had suffered from epilepsy for at least 1 year were included. Epilepsy types and seizures were classified according to the International League Against Epilepsy (16). A single unprovoked seizure was defined as epilepsy if specific EEG alterations or causal brain lesions identified by magnetic resonance imaging (MRI) indicated an increased and enduring risk for further epileptic seizures (17). Subjects were excluded from participation if they had experienced status epilepticus or acute symptomatic seizures exclusively, if they had a history of psychogenic non-epileptic seizures, or if cognitive deficits, mental retardation or German language barrier impeded adequate understanding and reply to the questions. Patients with legal representatives were also not enrolled.

Prior to the interview, each participant was educated on the scientific background and purpose of the study. We placed great importance on a relaxed and informal interview atmosphere, and each subject was thoroughly informed that all moral aspects regarding nicotine, alcohol, and illicit drug use were irrelevant and that all data would be made anonymous and remain confidential. Thereby, we attempted to increase subjects' receptivity to the questions and avoid patients answering the questions in a more socially acceptable way. In several testinterviews, patients were intimidated when being asked about nicotine, alcohol, and illicit drug intake in front of their companions. Therefore, all interviews were held in a separate study room where only the interviewer and the patient were present. To ensure a standard and informal interview situation all patients were interviewed by the same person (MiHa) who was not one of the treating physicians at the Epilepsy Outpatient Clinic.

Alcohol consumption usually represents a taboo in the doctorpatient relationship and questions on the smoking status are answered more easily. Therefore, subjects were first queried about nicotine consumption and only later asked to give details on alcohol use. Toward the end of the interview, patients were questioned on illicit drugs. Study subjects passed through the domains of the questionnaire with an increasing social stigma degree.

In the opening question on alcohol use, subjects were asked: "Do you have any experience with alcohol consumption?" For this question, patients were able to respond in their own words and did not have to choose a predetermined response option. The interviewer carefully noted the given information on the quantity and frequency of alcohol consumption in the opening question. Subjects who had consumed alcohol within the last 12 months stated details on alcohol intake in the opening question and later by specifying the quantity and frequency of their individual alcohol consumption. Using that approach, the reliability of patients' responses on alcohol use could be evaluated regarding consistency. Data were excluded, if the patients' responses were inconsistent, if subjects were too hesitant to answer the questions, or if patients had refused to give details in only one of the interview's topics, that is nicotine, alcohol drinking and illicit drug use. 


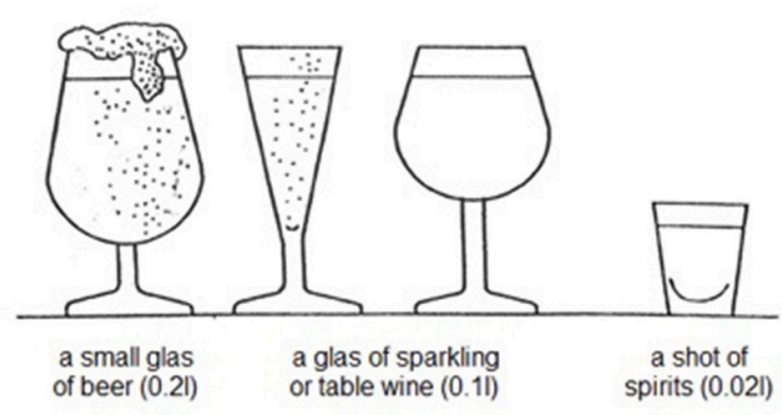

FIGURE 1 | Amounts of different alcoholic beverages that correspond to 1 standard drink as defined by the World Health Organization. This illustration has been shown to the participants of this study to guide them in estimating their individual average alcohol intake per drinking occasion.

To ensure a comparable evaluation, alcohol consumption was translated and expressed in standard drinks containing $10 \mathrm{~g}$ of pure alcohol (18). To assist subjects in measuring their individual average alcohol intake per drinking occasion, a chart illustrating different alcoholic beverages containing a single standard drink was shown to each study participant (Figure 1). Regarding the usual frequency of alcohol consumption within the last 12 months, subjects were able to choose one out of the following different categories: daily, almost daily, 1-2 times a week, 1-2 times a month or $<1-2$ times per month. According to that, patients who had consumed alcohol within the last 12 months were summarized in the following three alcohol drinking categories: Patients with alcohol intake of no more than 3-4 standard drinks daily, almost daily, 1-2 times per week or less than weekly were considered as light or occasional alcohol users. Moderate alcohol users were subjects who consumed more than occasional or light users but not more than 5-6 standard drinks daily, almost daily and not more than 9-10 standard drinks 1-2 times per week. Heavier alcohol use was considered as alcohol intake of more than 5-6 standard drinks daily, almost daily or more than 9-10 standard drinks 1-2 times per week. Alcohol abstinence was defined according to the World Health Organization (WHO) as a period of at least 12 months of nonconsumption ${ }^{1}$.

The Alcohol Use Disorder Identification Test (AUDIT) is a 10 -item core questionnaire developed by the WHO to identify hazardous and harmful alcohol intake (18) (Supplementary Material: questions 32-41), and was applied in all subjects who had consumed alcohol within the last 12 months. Patients are able to score up to a total of 40 points in domains like harmful alcohol intake and dependency symptoms. We considered patients as AUDIT-positive with AUDIT scores $\geq 8$. This cut-off has been found to provide an accurate measure of harmful alcohol drinking across age, gender, and cultures (19).

Apart from that, all interviewed subjects were asked what their trusted neurologist or physician had told them regarding alcohol consumption in the context of their epilepsy. Patients were able

\footnotetext{
${ }^{1}$ Lexicon of Alcohol and Drug Terms. WHO. Available online at: http://www.who. int/substance_abuse/terminology/who_lexicon/en/
}

to choose one out of four response options: (a) alcohol should be avoided completely, (b) alcohol can be consumed without any restriction, (c) light alcohol intake is harmless, or (d) no advice given by the physician.

\section{Alcohol-Related Seizures}

In this study, an alcohol-related seizure was defined as a seizure in the context of epilepsy that occurred within short temporal relation to alcohol use $(<24 \mathrm{~h})$. Alcohol users were asked "Do you have experienced an alcohol-related seizure within the last 12 months?" If patients had experienced an alcohol-related seizure in the last 12 months, they were requested to recall details on the quantity of alcohol intake prior to the seizure and on the time between cessation of alcohol intake and seizure manifestation $(<6 \mathrm{~h} / \geq 6-<12 \mathrm{~h} / \geq 12-<24 \mathrm{~h})$. The quantity of alcohol intake again was calculated and expressed in standard drinks to ensure a comparable evaluation (Figure 1). If patients had experienced more than one seizure related to alcohol use within the last 12 months, they were asked to state details on the seizure occurrence they remembered the best.

\section{Statistical Analysis}

Continuous data are presented as mean \pm standard deviation $(S D)$ or median where appropriate. Logistic regression analyses were used to calculate odds ratios with $95 \%$ confidence intervals as estimates for variables independently predicting alcohol use and the occurrence of alcohol-related seizures within the last 12 months.

In the logistic regression models, clinical data on patients' sex, age at interview, duration of epilepsy, epilepsy type, antiepileptic drug therapy, seizure frequency, alcohol drinking behavior over the last 12 months, and physicians' advice on alcohol use were included as possible confounding variables. In the results section of logistic regression analyses, findings were only noted if $95 \%$ CIs of the confounding variable did not include 1; if the $95 \% \mathrm{CI}$ included 1 , the corresponding variable was not significant and therefore was not pointed out. Statistical analyses were calculated using IBM SPSS statistics 24.0.

\section{RESULTS}

\section{Study Population}

The study population consisted of 310 patients with epilepsy (Table 1). Of these, seven subjects had suffered from only one single unprovoked seizure: In four of these patients remote structural brain lesions were demonstrated by neuroimaging indicating focal epilepsy. In one patient, interictal EEG findings were consistent with generalized genetic epilepsy, and in two subjects, EEG showed regional spikes and sharp waves without MRI structural brain lesions indicating focal epilepsy of unknown origin.

\section{Alcohol Consumption}

Out of 310 interviewed subjects, 204 (65.8\%) had used alcohol within the last 12 months, 158 (51\%) within the last 30 days, and $108(34.8 \%)$ within the last 7 days. Antiepileptic drug monotherapy (OR 1.901) and physicians' advice that a light alcohol intake is harmless (OR 4.102) were independent 
TABLE 1 | Characteristics of the study population $(n=310)$.

\begin{tabular}{|c|c|c|}
\hline Variable & & No. $(\%) /$ mean $\pm S D^{a}$ \\
\hline \multirow[t]{2}{*}{ Sex } & Female & $171(55.2)$ \\
\hline & Male & $139(44.8)$ \\
\hline Age (in years) & & $44.7 \pm 16.2$ \\
\hline $\begin{array}{l}\text { Duration of } \\
\text { epilepsy (in years) }\end{array}$ & & $20.1 \pm 16.8$ \\
\hline \multirow[t]{3}{*}{ Epilepsy type } & Focal & $213(68.7)$ \\
\hline & GGE $^{\mathrm{b}}$ & 67 (21.6) \\
\hline & Unknown & $30(9.7)$ \\
\hline \multirow[t]{3}{*}{$\mathrm{AED}^{\mathrm{C}}$} & Monotherapy & $184(59.4)$ \\
\hline & Polytherapy & $121(39.0)$ \\
\hline & No treatment & $5(1.6)$ \\
\hline \multirow[t]{2}{*}{ Seizure frequency } & $\geq 1 /$ month & $130(41.9)$ \\
\hline & $<1 /$ month & $180(58.1)$ \\
\hline \multirow[t]{3}{*}{$\begin{array}{l}\text { Alcohol use in the } \\
\text { last } 12 \text { months }\end{array}$} & $\begin{array}{l}\text { Alcohol abstinence } \\
\text { Occasional or light use }\end{array}$ & $\begin{array}{l}106(34.2) \\
147(47.4)\end{array}$ \\
\hline & Moderate use & $43(13.9)$ \\
\hline & Heavier use & $14(4.5)$ \\
\hline \multirow{4}{*}{$\begin{array}{l}\text { Physicians' advice } \\
\text { on the use of } \\
\text { alcohol }\end{array}$} & $\begin{array}{l}\text { Alcohol should be avoided } \\
\text { completely }\end{array}$ & $127(41.0)$ \\
\hline & No advice given & $94(30.3)$ \\
\hline & $\begin{array}{l}\text { Alcohol can be consumed } \\
\text { without restriction }\end{array}$ & $2(0.6)$ \\
\hline & Light alcohol intake is harmless & $87(28.1)$ \\
\hline
\end{tabular}

a $S D$, standard deviation.

${ }^{b}$ GGE, generalized genetic epilepsy.

${ }^{\mathrm{C}} A E D$, antiepileptic drug.

predictors for alcohol use within the last 12 months (Tables 2, 3). Out of the 204 patients who used alcohol, 147 (72\%) were occasional or light alcohol users, $43(21.1 \%)$ were moderate users and 14 subjects (6.9\%) practiced heavier alcohol use. Nine subjects of the study population (2.9\%) were AUDIT positive indicating hazardous and harmful alcohol use. All AUDIT positive subjects were heavier alcohol users.

Ninety-five patients (30.7\%) were alcohol-experienced but had been abstinent in the last year. Eleven subjects $11(3.5 \%)$ had never tried alcohol in their lifetime.

In alcohol-experienced subjects, who abstained from alcohol within the last 12 months $(n=95)$, epilepsy was reported to be the most common reason for no longer drinking alcohol ( $n=50 ; 52.6 \%$ ). Of those 50 patients, 49 subjects stated that they would consume alcohol if epilepsy had not been diagnosed and 16 patients stated that alcohol abstinence due to epilepsy is a challenge.

\section{Alcohol-Related Seizures}

Thirty-seven out of 204 alcohol users (18.1\%) had experienced alcohol-related seizures within the last 12 months (Table 4). In
$95 \%(n=35)$ of cases, these seizures had occurred within $12 \mathrm{~h}$ after cessation of alcohol intake.

In multivariate analysis, subjects with heavier alcohol use in the last 12 months were more likely to experience alcohol-related seizures (OR 8.955), whereas occasional or light and moderate alcohol use was not associated with increased risk for alcoholrelated seizures (Tables 5, 6). However, most of the patients (78.4\%) who reported alcohol-related seizures were occasional, light or moderate alcohol users who had changed their usual alcohol intake toward higher consumption on the drinking occasion prior to the seizures (Table 4). The amount of alcohol intake before the occurrence of alcohol-related seizures was very high in all of the cases with a mean of $13.3 \pm 5.8$ standard drinks (median 12.5, range 7-34), which is equivalent to $2.5 \mathrm{~L}$ of beer or $1.25 \mathrm{~L}$ of wine. The minimum was 7 standard drinks, equivalent to $\sim 1.4 \mathrm{~L}$ of beer or $0.7 \mathrm{~L}$ of wine.

Patients with generalized genetic epilepsy (OR 5.792) were more likely to experience alcohol-related seizures compared to patients with focal epilepsy (Tables 5, 6). In patients with focal epilepsy, the mean amount of alcohol intake prior to alcoholrelated seizures was $14.4 \pm 6.5$ (median 13, range 7.5-34) standard drinks, and in subjects with generalized genetic epilepsy $12.3 \pm 5.9$ (median 11.3, range 7-30). No significant difference was detected $(p=0.366)$.

In female patients, the mean amount of alcohol intake before alcohol-related seizures was $10.9 \pm 3.1$ standard drinks (median 11.3, range 7-15), and in male subjects, $15.4 \pm 6.8$ (median 15, range $7.5-34 ; p=0.02$ ).

Fifteen out of 95 (15.8\%) alcohol-experienced but now abstinent subjects had experienced alcohol-related seizures in the past. In that group, the mean amount of alcohol intake prior to the seizures was 10.9 standard drinks. All of these patients stated that they had stopped alcohol consumption because of the experience of alcohol-related seizures.

\section{DISCUSSION}

In this study, we aimed to systematically analyze alcohol drinking and the occurrence of alcohol-related seizures in 310 epilepsy patients. Even though alcohol use may trigger seizures, 65\% of interviewed subjects had consumed alcohol within the last 12 months and every third patient had consumed alcohol within the last 7 days. Our results are in line with previous population-based study findings from Canada reporting a 12month prevalence of alcohol use in patients with epilepsy of $57.6 \%$ (20). In our study, most subjects were occasional or light alcohol users. Regarding chronic heavy alcohol consumption, our cohort of patients had used alcohol far more responsibly than the general adult German population. Only $2.9 \%$ of our interviewed study subjects were AUDIT positive indicating hazardous and harmful alcohol intake. By contrast, data from the general adult German population showed that a proportion of $19.7 \%$ is AUDIT positive (9).

In multivariate analysis, alcohol consumption within the last 12 months was independently related to AED monotherapy. It is highly likely that subjects with well-controlled epilepsies on 
TABLE 2 | Possible confounding variables that were included in the logistic regression model regarding alcohol consumption within the last 12 months.

\begin{tabular}{|c|c|c|c|}
\hline \multirow[t]{2}{*}{ Variable } & & \multirow{2}{*}{$\frac{\text { Alcohol use within the last } 12 \text { months }(n=204)}{\text { No. }(\%) / \text { mean } \pm S D^{a}}$} & \multirow{2}{*}{$\frac{\text { Alcohol-abstinence }(n=106)}{\text { No. }(\%) / \text { mean } \pm S D}$} \\
\hline & & & \\
\hline \multirow[t]{2}{*}{ Sex } & Female & 108 (52.9) & $63(59.4)$ \\
\hline & Male & $96(47.1)$ & 43(40.6) \\
\hline \multicolumn{2}{|l|}{ Age (in years) } & $43.8 \pm 15.9$ & $46.3 \pm 16.7$ \\
\hline \multicolumn{2}{|c|}{ Duration of epilepsy (in years) } & $18.9 \pm 15.8$ & $22.5 \pm 18.4$ \\
\hline \multirow[t]{3}{*}{ Epilepsy type } & Focal & $135(66.2)$ & 78 (73.6) \\
\hline & $\mathrm{GGE}^{\mathrm{b}}$ & $45(22.1)$ & $22(20.8)$ \\
\hline & Unknown & $24(11.7)$ & $6(5.6)$ \\
\hline \multirow[t]{3}{*}{$\mathrm{AED}^{\mathrm{C}}$} & Monotherapy & $130(63.7)$ & $54(50.9)$ \\
\hline & Polytherapy & $69(33.8)$ & $52(49.1)$ \\
\hline & No treatment & $5(2.5)$ & 0 \\
\hline \multirow[t]{2}{*}{ Seizure frequency } & $\geq 1 /$ month & $76(37.3)$ & $54(50.9)$ \\
\hline & $<1 /$ month & $128(62.7)$ & $52(49.1)$ \\
\hline \multirow[t]{4}{*}{ Physicians' advice } & Alcohol should be avoided completely & $73(35.8)$ & $54(51)$ \\
\hline & No advice & $56(27.4)$ & $38(35.8)$ \\
\hline & Alcohol can be consumed without restriction & $2(1)$ & 0 \\
\hline & Light alcohol intake is harmless & $73(35.8)$ & $14(13.2)$ \\
\hline
\end{tabular}

a $S D$, standard deviation.

${ }^{b}$ GGE, generalized genetic epilepsy.

${ }^{c} A E D$, antiepileptic drug treatment.

TABLE 3 | Independent predictors for alcohol consumption within the last 12 months.

\begin{tabular}{|c|c|c|c|c|}
\hline Variable & & $\mathrm{OR}^{\mathrm{a}}$ & $95 \% \mathrm{Cl}^{\mathrm{b}}$ & $P$-value \\
\hline \multirow[t]{3}{*}{$A E D^{C}$} & Polytherapy & 1.0 (ref.) & & \\
\hline & Monotherapy & 1.901 & $1.152-3.138$ & $p=0.012$ \\
\hline & None & $N / A^{d}$ & $\mathrm{~N} / \mathrm{A}$ & $\mathrm{N} / \mathrm{A}$ \\
\hline \multirow[t]{4}{*}{$\begin{array}{l}\text { Physicians' } \\
\text { advice }\end{array}$} & $\begin{array}{l}\text { Alcohol should be } \\
\text { avoided completely }\end{array}$ & 1.0 (ref.) & & \\
\hline & $\begin{array}{l}\text { Alcohol can be } \\
\text { consumed without } \\
\text { restriction }\end{array}$ & $\mathrm{N} / \mathrm{A}$ & $\mathrm{N} / \mathrm{A}$ & $\mathrm{N} / \mathrm{A}$ \\
\hline & No advice & 1.043 & $0.599-1.814$ & $p=0.883$ \\
\hline & $\begin{array}{l}\text { Light alcohol intake is } \\
\text { harmless }\end{array}$ & 4.102 & 2.078-8.097 & $p<0.0001$ \\
\hline
\end{tabular}

${ }^{a} \mathrm{OR}$, odds ratio.

${ }^{b} \mathrm{Cl}$, confidence interval.

${ }^{c} A E D$, antiepileptic drug treatment.

${ }^{\mathrm{N}} / \mathrm{A}$, not available.

monotherapy are more likely to consume alcoholic beverages than those with difficult-to-treat variants. Physicians' advice that "a light alcohol intake is harmless" was identified as an additional predictor for alcohol use. Patients with epilepsy may feel unsure about alcohol consumption on chronic medication and therefore may be willing to follow physicians' advices more often.
Thirty-seven out of 204 epilepsy patients who had consumed alcohol remembered that they had experienced an alcohol-related seizure within the last 12 months. These seizures occurred in the timely context of acute heavy alcohol consumption. The occurrence of seizures in short temporal relation to alcohol consumption may not prove that these seizures were necessarily causally related to alcohol use. The following arguments however support this hypothesis: Most subjects with alcohol-related seizures were occasional, light or moderate alcohol users but a noticeable change in their usual alcohol-drinking behavior toward higher consumption prior to the seizures could be documented. This taken together with the fact that almost all alcohol-related seizures (95\%) had occurred within the first $12 \mathrm{~h}$ after cessation of alcohol intake support a causal relationship between alcohol use and temporally close seizure manifestation in these cases.

In the study population, generalized genetic epilepsy was an independent predictor for the occurrence of alcohol-related seizures. The mean alcohol intake prior to alcohol-related seizures was not higher in patients with generalized genetic epilepsy than in subjects with focal epilepsy. Lennox stated that alcohol-related seizures had occurred more often in patients with symptomatic than in cryptogenic or idiopathic epilepsies (1). The then applied syndromatic allocation, however, may not be in exact conformance with the present classifications $(16,17)$. Janz (21) later observed that alcohol-related seizures were more likely to occur in subjects with generalized genetic epilepsy 
TABLE 4 | Clinical variables of patients with epilepsy who had experienced alcohol-related seizures within the last 12 months $(n=37)$.

\begin{tabular}{|c|c|c|c|c|}
\hline Patient-ID & $\begin{array}{l}\text { Alcohol intake prior to alcohol-related } \\
\text { seizures (standard drinks) }\end{array}$ & $\begin{array}{l}\text { Time between cessation of alcohol } \\
\text { intake and seizure occurrence (range } \\
\text { in hours) }\end{array}$ & $\begin{array}{l}\text { Usual alcohol-drinking behavior within } \\
\text { the last } 12 \text { months }\end{array}$ & Epilepsy type \\
\hline \#25 & 8.75 & $<6$ & Occasional or light use & $\mathrm{GGE}^{\mathrm{a}}$ \\
\hline \#31 & 15 & $\geq 6-<12$ & Occasional or light use & Focal \\
\hline \#32 & 10 & $\geq 6-<12$ & Occasional or light use & Focal \\
\hline$\# 40$ & 7 & $\geq 6-<12$ & Moderate use & GGE \\
\hline \#53 & 12 & $<6$ & Occasional or light use & Focal \\
\hline$\# 54$ & 17.5 & $<6$ & Occasional or light use & Focal \\
\hline \#63 & 15 & $\geq 6-<12$ & Occasional or light use & GGE \\
\hline \#65 & 12.5 & $\geq 6-<12$ & Moderate use & GGE \\
\hline \#116 & 7.5 & $<6$ & Occasional or light use & Focal \\
\hline \#133 & Not remembered & $<6$ & Heavier use & Focal \\
\hline \#140 & 12.5 & $<6$ & Moderate use & GGE \\
\hline \#141 & Not remembered & $\geq 6-<12$ & Heavier use & Focal \\
\hline \#144 & 12.5 & $\geq 6-<12$ & Occasional or light use & Focal \\
\hline \#147 & 15 & $<6$ & Occasional or light use & Focal \\
\hline \#154 & 10 & $\geq 12-<24$ & Moderate use & Focal \\
\hline \#178 & 15 & $<6$ & Occasional or light use & Unknown \\
\hline \#185 & 15 & $<6$ & Heavier use & Unknown \\
\hline \#188 & 14.5 & $<6$ & Occasional or light use & Focal \\
\hline \#278 & 12.5 & $<6$ & Occasional or light use & GGE \\
\hline \#280 & 13 & $\geq 6-<12$ & Occasional or light use & Focal \\
\hline \#282 & 7.5 & $\geq 6-<12$ & Occasional or light use & Unknown \\
\hline \#283 & 10 & $<6$ & Occasional or light use & GGE \\
\hline \#291 & 8.75 & $<6$ & Moderate use & GGE \\
\hline \#308 & 15 & $\geq 6-<12$ & Heavier use & Focal \\
\hline
\end{tabular}

${ }^{a} G G E$, generalized genetic epilepsy.

than in those with focal epilepsy, which is consistent with our findings (21).

Acute alcohol consumption suppresses central nervous excitability by activating the inhibitory GABA-system (22). GABA is the major inhibitory neurotransmitter in the brain. Furthermore, alcohol inhibits glutamate activity, which is the major excitatory neurotransmitter of the CNS. Thus in subjects with epilepsy, alcohol intake initially reduces CNS epileptiform EEG-activity. Later however, when alcohol blood levels decline, epileptiform EEG-activity has been shown to be increased which is associated with a higher risk for seizures $(4-6,23)$. In an experimental study on mice with chronic epilepsy, seizure thresholds were measured after the administration of ethanol. Initially, anticonvulsant properties of ethanol were observed, but later a transient lowering of seizure thresholds and hypersusceptibility to seizures were reported (7).

In patients with generalized genetic epilepsy, seizures commonly manifest within $30 \mathrm{~min}$ after awakening. A transcranial magnetic stimulation study on patients with genetic generalized epilepsy demonstrated that motor cortex excitability was significantly increased in the early morning (24). In subjects with generalized genetic epilepsy, this increased 


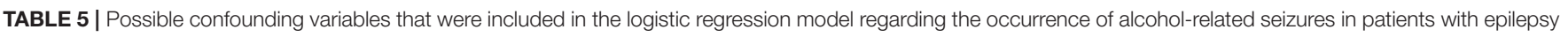
within the last 12 months.

\begin{tabular}{|c|c|c|c|}
\hline \multirow[t]{2}{*}{ Variable } & & \multirow{2}{*}{$\begin{array}{c}\text { Alcohol-related seizure occurrence } \\
\text { within the last } 12 \text { months }(n=37) \\
\text { No. }(\%) / \text { mean } \pm S D^{a}\end{array}$} & \multirow{2}{*}{$\begin{array}{l}\text { No alcohol-related seizures within the } \\
\text { last } 12 \text { months }(n=167) \\
\text { No. }(\%) / \text { mean } \pm S D\end{array}$} \\
\hline & & & \\
\hline \multirow[t]{2}{*}{ Sex } & Female & $17(45.9)$ & $91(54.5)$ \\
\hline & Male & $20(54.1)$ & $76(45.5)$ \\
\hline Age (in years) & & $40.7 \pm 14.7$ & $44.5 \pm 16.1$ \\
\hline Duration of epilepsy (in years) & & $20.3 \pm 15.1$ & $18.6 \pm 16$ \\
\hline \multirow[t]{3}{*}{ Epilepsy type } & Focal & $15(40.6)$ & $120(71.9)$ \\
\hline & $\mathrm{GGE}^{\mathrm{b}}$ & $17(45.9)$ & $28(16.8)$ \\
\hline & Unknown & $5(13.5)$ & $19(11.3)$ \\
\hline \multirow[t]{3}{*}{$\mathrm{AED}^{\mathrm{C}}$} & Monotherapy & $22(59.5)$ & $108(64.7)$ \\
\hline & Polytherapy & $14(37.8)$ & 55 (32.9) \\
\hline & No treatment & $1(2.7)$ & $4(2.4)$ \\
\hline \multirow[t]{2}{*}{ Seizure frequency } & $\geq 1 /$ month & $13(35.1)$ & $63(37.7)$ \\
\hline & $<1 /$ month & $24(64.9)$ & $104(62.3)$ \\
\hline \multirow[t]{3}{*}{ Alcohol use within the last 12 months } & Occasional or light use & $22(59.5)$ & $125(74.8)$ \\
\hline & Moderate use & $7(18.9)$ & $36(21.6)$ \\
\hline & Heavier use & $8(21.6)$ & $6(3.6)$ \\
\hline
\end{tabular}

a $S D$, standard deviation.

${ }^{b} \mathrm{GGE}$, generalized genetic epilepsy.

${ }^{c} A E D$, antiepileptic drug.

TABLE 6 | Independent predictors for the occurrence of alcohol-related seizures within the last 12 months in patients with epilepsy.

\begin{tabular}{llccc}
\hline Variable & & OR $^{\mathbf{a}}$ & $\mathbf{9 5 \%} \mathbf{C l}^{\mathbf{b}}$ & $\boldsymbol{P}$-value \\
\hline Epilepsy type & Focal & 1.0 (ref.) & & \\
& GGE $^{\mathrm{N}}$ & 5.792 & $2.427-13.823$ & $p<0.0001$ \\
& Unknown & 2.185 & $0.664-7.189$ & $p=0.198$ \\
\hline \multirow{2}{*}{$\begin{array}{l}\text { Alcohol use within } \\
\text { the last 12 months }\end{array}$} & Occasional or light & 1.0 (ref.) & & \\
& use & & & \\
& Moderate use & 0.819 & $0.306-2.194$ & $p=0.691$ \\
& Heavier use & 8.955 & $2.625-30.545$ & $p<0.0001$ \\
\hline
\end{tabular}

${ }^{a} \mathrm{OR}$, odds ratio.

${ }^{b} \mathrm{Cl}$, confidence interval.

${ }^{c}$ GGE, generalized genetic epilepsy.

neuronal excitability in the early morning may be potentiated by the hyper-excitable post-alcohol state, and this effect may be responsible for the increased susceptibility to alcohol-related seizures compared to focal epilepsy.

\section{Clinical Perspective}

Most of our interviewed subjects ( $>80 \%$ ) that consumed alcohol within the last 12 months did not experience alcohol-related seizures. Current data on the quantity of alcohol intake prior to the occurrence of alcohol-related seizures in patients with epilepsy highly suggest that these situations are related to the acute consumption of considerably large amounts of alcohol. Subjects who reported alcohol-related seizures had consumed at least 7 standard drinks before seizures occurred which is equivalent to $1.4 \mathrm{~L}$ of beer or $0.7 \mathrm{~L}$ of wine. Occasional or light and moderate alcohol-drinking behavior was not associated with alcohol-related seizure occurrences. In the general German population, $89 \%$ of all adults had used alcohol within the last 12 months, only $8 \%$ were alcohol-experienced but abstinent, and $3 \%$ had never used alcohol in their lifetime (9). In the present study, $30.7 \%$ of patients were alcohol-experienced but abstinent and 3.5\% had never consumed alcohol in their lifetime. Therefore, the proportion of alcohol-experienced but abstinent subjects with epilepsy was almost four times higher than in the general population. Epilepsy was often stated to be the only reason for alcohol-abstinence, which felt challenging to many subjects. Alcohol abstinence may not be necessary as long as epilepsy patients practice a responsible alcohol intake. Subjects with generalized genetic epilepsy however should be made aware of their increased susceptibility to alcohol-related seizures.

\section{Limitations}

Our systematic data collection based on personal interviews allowed us to provide updated knowledge on the patterns of 
alcohol drinking and the occurrence of alcohol-related seizures in a large cohort of 310 epilepsy patients.

Several limitations have to be discussed. First, our data on alcohol use depended on patients' self-reporting and may be affected by recall bias. It has been demonstrated that assessing alcohol consumption is biased by recall even when the recall period is only 1 week (25). In our study population, alcohol consumption is probably underestimated. However, this does not impact our main findings. Moreover, patients were seen at our institution at scheduled outpatient visits and did not attend the clinic after acute manifestations of alcohol-related seizures. Only a minority of patients documented details on alcohol-related seizures in seizure diaries. Our retrospective data collection on alcohol-related seizures also depended on subjects' recall capability, and may reflect bias due to recall errors. We addressed this by focusing only on alcohol-related seizures that had occurred within the last 12 months. Details were only recorded on those alcohol-related seizures that subjects were able to remember the best. As a consequence however, alcohol-related seizures may have also occurred after smaller amounts of alcohol intake or in other circumstances that were not taken into account in the present study.

Second, as patients were interviewed retrospectively on the occurrence of alcohol-related seizures, we were not able to provide data on AED drug levels after the acute manifestation of these seizures. We cannot exclude that subjects might have been more prone to seizure occurrences due to AED non-adherence. Furthermore, we cannot exclude hypoglycemic episodes caused by acute heavy alcohol consumption (26), which may have contributed to the manifestation of epileptic seizures (27).

Third, other studies have shown that alcohol consumption and especially the consumption of considerable large amounts of alcohol may reduce sleep quality by increasing light sleep and wake-up periods during the second half of the night time sleep period $(28,29)$. In addition to that, alcohol intake significantly suppresses REM sleep periods (30). Reduced sleep quality and consecutive sleep deprivation have long been discussed to facilitate the occurrence of seizures in patients with epilepsy (31), and especially in those with generalized genetic epilepsy (3234). Altered sleep architecture due to acute alcohol consumption

\section{REFERENCES}

1. Lennox WG. Alcohol and epilepsy. Q J Stud Alcohol. (1941) 2:1-11.

2. Höppener RJ. The effect of social alcohol use on seizures in patients with epilepsy. In: Porter RJ, Mattson RH, Cramer JA, Diamond I. editors. Alcohol and Seizures: Basic Mechanisms and Clinical Concepts. Philadelphia, PA: FA Davis (1990). p. 222-32.

3. Mattson RH, Fay ML, Sturman JK, Cramer, JA Wallace, JD Mattson, EM. The effects of various patterns of alcohol use on seizures in patients with epilepsy. In: Porter RJ, Mattson RH, Cramer JA, Diamond I, editors. Alcohol and Seizures: Basic Mechanisms and Clinical Concepts. Philadelphia, PA: FA Davis (1990). p. 233-40.

4. Vossler DG, Browne TR. The electroencephalogram in patients with alcoholrelated seizures. In: Porter RJ, Mattson RH, Cramer JA, Diamond I, editors. Alcohol and Seizures: Basic Mechanisms and Clinical Concepts. Philadelphia, PA: FA Davis (1990). p. 179-96. constitutes a non-negligible and important co-factor for seizure risk in patients with epilepsy. Due to the retrospective design of the present study, we were not able to assess sleep quality prior to alcohol-related seizure occurrences. Future prospective research, e.g., using polysomnography, will be needed to provide insight into the complex relationship between alcohol consumption, altered sleep architecture and timely manifestation of seizures.

Finally, the present study population was exclusively recruited at a tertiary care epilepsy center where usually patients with more severe variants of the disease are treated. This indicates a potential selection bias and our results may not be generalized to all epilepsy patients without restrictions.

\section{ETHICS STATEMENT}

The study was approved by the local Institutional Review Board (EA 1/146/08), and signed informed consent was obtained from all participants.

\section{AUTHOR CONTRIBUTIONS}

$\mathrm{MiH}$ : data collection, statistical, analysis, wrote manuscript. LG, $\mathrm{AK}$, and FW helped recruiting patients, helped to improve manuscript. $\mathrm{MaH}$ : statistical analysis, wrote manuscript.

\section{ACKNOWLEDGMENTS}

$\mathrm{MaH}$ holds the Friedrich-von-Bodelschwingh endowed Professorship for Clinical and Experimental Epileptology at the Charité-Universitätsmedizin Berlin funded by von Bodelschwingh Foundation. Statistical analyses were conducted with the help of Martin Donhauser, Ph.D., Department of Statistics, University of Regensburg. We thank David Richard Urry for helpful comments in editing the manuscript.

\section{SUPPLEMENTARY MATERIAL}

The Supplementary Material for this article can be found online at: https://www.frontiersin.org/articles/10.3389/fneur. 2018.00401/full\#supplementary-material

5. Ticku MK. The effects of acute and chronic ethanol administration and its withdrawal on gamma-aminobutyric acid receptor binding in rat brain. $\mathrm{Br} \mathrm{J}$ Pharmacol. (1980) 70:403-10. doi: 10.1111/j.1476-5381.1980.tb08716.x

6. Nagy L, Zsadanyi O, Nagy J, Zsigmond, K. Cerebral electrical phenomena elicited by alcohol. Z Rechtsmed. (1973) 73:185-90. doi: 10.1007/BF02116822

7. McQuarrie DG, Fingl, E. Effects of single doses and chronic administration of ethanol on experimental seizures in mice. J Pharmacol Exp Ther. (1958) 124:264-71.

8. WHO. Global Status Report on Alcohol and Health 2011. Geneva: World Health Organization (2011).

9. Papst A, Kraus L. Alkoholkonsum, alkoholbezogene Störungen und Trends. Ergebnisse des Epidemiologischen Suchtsurveys 2006. Sucht (2008) 54:36-46. doi: 10.1024/2008.07.05

10. Victor M, Adams RD. The effect of alcohol on the nervous system. Res Publ AssocRes Nerv Ment Dis. (1953) 32:526-73.

11. Victor M, Brausch, C. The role of abstinence in the genesis of alcoholic epilepsy. Epilepsia (1967) 8:1-20. doi: 10.1111/j.1528-1157.1967.tb03815.x 
12. McKeon A, Frye MA, Delanty N. The alcohol withdrawal syndrome. JNNP (2008) 79:854-62. doi: 10.1136/jnnp.2007.128322

13. Samokhalov AV, Irving H, Mohapatra S, Rehm J. Alcohol consumption, unprovoked seizures, and epilepsy: a systematic review and meta-analysis. Epilepsia (2010) 51:1177-84. doi: 10.1111/j.1528-1167.2009.02426.x

14. Dworetzky BA, Bromfield EB, Townsend MK, Kang JH. A prospective study of smoking, caffeine, and alcohol as risk factors for seizures or epilepsy in young adult women: data from the Nursus' Health Study II. Epilepsia (2010) 51:198-205. doi: 10.1111/j.1528-1167.2009.02268.x

15. Hamerle M, Ghaeni L, Kowski A, Weissinger F, Holtkamp M. Cannabis and other illicit drug use in epilepsy patients. Eur J Neurol. (2014) 21:167-70. doi: 10.1111/ene.12081

16. Scheffer IE, Berkovic S, Capovilla, G, Connolly MB, French J, Guilhoto L, et al. ILAE classification of the epilepsies: Position paper of the ILAE Commission for Classification and Terminology. Epilepsia (2017) 58:512-21. doi: 10.1111/epi.13709

17. Fisher RS, Acevedo C, Arzimanoglou, A. Bogacz A, Cross JH, Elger CE, et al. ILAE official report: a practical clinical definition of epilepsy. Epilepsia (2014) 55:475-82. doi: 10.1111/epi.12550

18. Saunders JB, Aasland OG, Babor TF, De la Fuente JR, Grant, M. Development of the Alcohol Use Disorder Indentification Test (AUDIT): WHO collaborative project on early detection of persons with harmful alcohol consumption-II. Addiction (1993) 88:791-804. doi: 10.1111/j. 1360-0443.1993.tb02093.x

19. Allen JP, Litten RZ, Fertig JB, Babor, T. A review of research on the Alcohol Use Disorders Identification Test (AUDIT). Alcohol Clin Exp Res. (1997) 21:613-19. doi: 10.1111/j.1530-0277.1997.tb03811.x

20. Hinnell C, Williams J, Metcalfe, A. Patten SB, Parker R, Wiebe S, et al. Health status and health-related behaviors in epilepsy compared to other chronic conditions-a national population-based study. Epilepsia (2010) 51:853-61. doi: 10.1111/j.1528-1167.2009.02477.x

21. Janz D. Die Epilepsien: Spezielle Pathologie und Therapie. 1st ed. Stuttgart; New York, NY: Georg Thieme Verlag (1969).

22. Mehta AK, Ticku MK. Ethanol potentiation of GABAergic transmission in cultured spinal cord neurons involves gamma-aminobutyric acidA-gated chloride channels. J Pharmacol Exp Ther. (1988) 246:558-64.

23. Rodin EA, Frohman CE, Gottlieb JS. Effect of acute alcohol intoxication on epileptic patients. Arch Neurol. (1961) 4:103-6. doi: 10.1001/archneur.1961.00450070105012

24. Badawy RAB, MacDonell RAL, Jackson GD, Berkovic SF. Why do seizures in generalized epilepsy often occur in the morning? Neurology (2009) 73:218-22. doi: 10.1212/WNL.0b013e3181ae7ca6
25. Ekholm O, Strandberg-Larsen K, Gronbaek, M. Influence of the recall period on a beverage-specific weekly drinking measure for alcohol intake. Eur J Clin Nutr. (2011) 65:520-5. doi: 10.1038/ejcn.2011.1

26. Field JB, Williams HE, Mortimore GE. Studies on the mechanism of ethanol-induced hypoglycaemia. J Clin Invest. (1963) 42:497-506. doi: 10.1172/JCI104738

27. Beghi, E. Carpio A, Forsgren L, Hesdorffer DC, Malmgren K, Sander JW, et al. Recommendation for a distinction of acute symptomatic seizures. Epilepsia (2010) 54:671-75. doi: 10.1111/j.1528-1167.2009.02285.x

28. Williams DL, MacLean AW, Cairns, J. Dose-response effects of ethanol on the sleep of young women. J Stud Alcohol. (1983) 44:515-23. doi: $10.15288 /$ jsa. 1983.44 .515

29. Roehrs T, Yoon J, Roth T. Nocturnal and next-day effects of ethanol and basal level of sleepiness. Human Psychopharmacol Clin Exp. (1991) 6:307-11. doi: 10.1002/hup.470060407

30. Williams H, Salamy A. Alcohol and sleep. In: Kissin B, Begleiter H, editors. The Biology of Alcoholism. New York, NY: Plenum Press (1972). p.435-83.

31. Chihorek AM, Abou-Khalil B, Malow BA. Obstructive sleep apnea is associated with seizure occurrence in older adults with epilepsy. Neurology (2007) 69:1823-7. doi: 10.1212/01.wnl.0000279334.78298.d5

32. Janz, D. The grand mal epilepsies and the sleep-waking cycle. Epilepsia (1962) 3:69-109. doi: 10.1111/j.1528-1157.1962.tb05235.x

33. Pedersen SB, Petersen KA. Juvenile myoclonic epilepsy: clinical and EEG feaures. Acta Neurol Scand. (1998) 97:160-3. doi: 10.1111/ j.1600-0404.1998.tb00630.x

34. Bråthen G, Ben-Menachem E, Brodtkorb E, Galvin R, Garcia-Monco JC, Halasz P, et al. EFNS guideline on the diagnosis and management of alcoholrelated seizures: report of an EFNS task force. Eur J Neurol. (2005) 12:575-81. doi: 10.1111/j.1468-1331.2005.01247.x

Conflict of Interest Statement: The authors declare that the research was conducted in the absence of any commercial or financial relationships that could be construed as a potential conflict of interest.

Copyright (C) 2018 Hamerle, Ghaeni, Kowski, Weissinger and Holtkamp. This is an open-access article distributed under the terms of the Creative Commons Attribution License (CC BY). The use, distribution or reproduction in other forums is permitted, provided the original author(s) and the copyright owner are credited and that the original publication in this journal is cited, in accordance with accepted academic practice. No use, distribution or reproduction is permitted which does not comply with these terms. 